\title{
Government Workers' Stories about Professional Development in a Digitalized Working Life
}

\author{
Anna Wallin ${ }^{1}$ (1) $\cdot$ Laura Pylväs ${ }^{2}$ (1) $\cdot$ Petri Nokelainen ${ }^{1}$ (D)
}

Received: 24 May 2019 / Accepted: 20 March 2020/ Published online: 1 April 2020

(C) The Author(s) 2020

\begin{abstract}
In this article, we explore workers' stories about digitalization of work and professional development. The data (101 stories) were collected from 81 Finnish government workers through the method of empathy-based stories (MEBS). MEBS is a qualitative data collection method in which participants write short imaginary texts based on an introductory script (frame story) designed by the researcher. In this study, participants were presented with two frame stories in which they were asked to imagine why digitalization had either supported or hindered professional development. The stories were analyzed inductively using qualitative thematic analysis. The findings illustrate the double-edged nature of digitalization, as it may both support and hinder professional development and learning by changing work tasks, work practices and knowledge development and management. Overall, the stories revealed that the participants perceived that digitalization may support professional development and learning, especially by providing opportunities for job control in terms of flexibility, and new ways for knowledge development and management.
\end{abstract}

Keywords Professional development · Professional learning · Workplace learning · Digitalization · The method of empathy-based stories

\section{Introduction}

The nature of work has changed profoundly and continues to do so for a range of issues, including globalization, automation, and digitalization. The growing use of information and communication technology (ICT) is slated to remodel the nature of work, as it enables

Anna Wallin

Anna.wallin@tuni.fi

1 Faculty of Education and Culture, Tampere University, 33014 Tampere, Finland

2 Faculty of Educational Sciences, University of Helsinki, Siltavuorenpenger 1B, Psychologicum, P.O. Box 9, 00014 Helsinki, Finland 
efficient and fast knowledge flow, autonomous work tasks, synchronicity, mobility, independence, and co-creation. Furthermore, from a corporate point of view, digitalization is expected to enhance productivity, efficiency, and knowledge use in organizations. However, digitalization might also lead to information overload, challenges of time management, fragmented work settings, procrastination, and technological shortcomings (Vuori, Helander, and Okkonen 2018). In all, advances in technology and an expanded knowledge economy require individuals to "adapt to working within newly structured, distributed, dynamic environments that are technologically-mediated" (Littlejohn, Milligan, and Margaryan 2012, p. 227). Adopting new technologies changes work tasks and work practices in many ways, which further influences the factors affecting learning at work, such as job demands, job control and social support (Fisher et al. 2018). Thus, digital changes pose new challenges for workers and require them to learn and develop constantly in order to maintain and improve their capacity for effectiveness.

Although several institutions have provided possible scenarios in relation to the impact of digitalization on working life (e.g., Muro et al. 2017), empirical research investigating digitalization and professional development is still scarce (e.g., Eteläpelto 2017; Fisher et al. 2018; Harteis 2018). Overall, professional development research has traditionally focused on professional development programs and training courses. Recent studies have called for a shift in focus from formal processes of education and training to learning experiences in the workplace and professional settings (e.g., Havnes and Smeby 2014; Webster-Wright 2009). Empirical studies in work contexts have often applied such traditional methods as interviews and surveys. However, it has been stated that in personal interviews, interviewees are more likely to answer in a socially desirable way and be more agreeable in interview situations (e.g., Janis 1982; Krumpal 2013; Schuman and Presser 1981; van der Heijden et al. 2000) and thus, the lack of face-to-face interaction with the researchers can be regarded as an asset. As digitalization is a value-laden and possibly sensitive topic, in this study we have applied a novel qualitative method of empathy-based stories (MEBS) that may allow the participants to express themselves with less external pressure. A third-person perspective in narratives aimed to provide the participants an opportunity to step out of themselves to expand their experiences and imagination (see Wallin et al. 2018). In this article we respond to the above-mentioned calls by studying how digitalization might shape work tasks and professional development in the future. More specifically, in this research, the interest is in exploring Finnish government workers $(N=81)$ and their perceptions, to address the following research questions:

1) How is work influenced by digitalization in government workers'stories?

2) How is professional development supported and hindered by digitalization in government workers' stories?

\section{Professional Development and Learning in a Digitalized Working Place}

\section{Professional Development}

Several terms are used to describe the generic field of professional development, such as continuing professional development or continuing professional learning. It also 
includes diverse, and potentially conflicting framings and approaches (Havnes and Smeby 2014). The field has been especially dominated by a training model through which the focus is on professional development programs and training courses rather than learning experiences in the workplace and professional settings (Webster-Wright 2009). According to Webster-Wright's critical review, "the term 'PD' [professional development] is part of a discourse that focuses on professionals as deficient and in need of developing and directing rather than on a professional engaged in self-directed learning" (2009, p. 712).

It thus follows that scholars have called for a shift in focus from professional development to professional learning, with work itself as the focal point, alongside the "notion of learning as situated in social practice, institutional cultures and structures in which learning revolves around work" (Havnes and Smeby 2014, p. 932; see also Timperley 2011; Webster-Wright 2009). Consequently, the range of possible learning activities related to professional development has been broadened. Today, this range includes both the informal and unintended activities (e.g., observing, listening) of the workplace as well as formal and intended ones (e.g., guiding, mentoring, courses) (e.g., Cheetham and Chivers 2001; Collin, Van der Heijden, and Lewis 2012). Thus, the current view is that professional development and learning are achieved through participation in everyday work activities, and the responsibility for learning has shifted from the training department to the professionals themselves (e.g., Billett 2015; Billett and Noble 2017; Littlejohn et al. 2016; Poell et al. 2018).

In previous research on workplace learning, much emphasis has been placed on the opportunities and affordances different social and physical circumstances offers workers (e.g., Ellstrom 2011; Eraut 2007; Fuller and Unwin 2004). It has been found that "the readiness of the workplace to afford opportunities for individuals to participate in work activities and access direct and indirect support are key determinants in the quality of learning that arises from that learning" (Billett 2001, p. 209). According to Ellstrom (2001), the learning potential of a workplace is determined by a complex interplay of several factors. Such factors include: (a) task characteristics, for example, task complexity, variety and control; (b) opportunities for feedback, evaluation and reflection; (c) the type and degree of formalization of work processes; (d) organizational arrangements for employee participation in problem handling and developmental activities; and (e) learning resources in terms of, for example, time for analysis, interaction and reflection (Ellstrom 2011, p. 108).

Likewise, Eraut (2007) has identified three interrelated context factors and learning factors, which play a significant role in building a learning-intensive work environment. The learning factors include 1) the professional's confidence and commitment, 2) challenges in one's work, and 3) feedback and support. According to Eraut (2007), learning at work "occurs through doing things and being proactive in seeking learning opportunities, and this requires confidence" (p. 269). Moreover, challenges in one's work need confidence, which in turn is dependent on how learners feel supported in meeting challenges in one's work. In addition to learning factors, context factors also affect learning in the workplace, and these include: 1) allocation and structuring of work, 2) expectations of each person's role, performance and progress, and 3) encounters and relationships with people at work. These factors highlight the importance of the organization of work within the organization, as well as the role of managers and social relationships in facilitating learning. 
The above described factors can also be found in the demand-control-support model (DCS) (Johnson and Hall 1988; Karasek 1979; see also Fisher et al. 2018), which proposes that for attaining high levels of learning opportunities, workplaces should afford their workers with highly demanding work activities, high levels of job control and social support. In the DCS model, a demanding job consists of high task variety, task complexity and a requirement for problem solving. Job control refers to the opportunities a worker has in regard to "(a) method autonomy, the discretion to choose different methods or means to accomplish a work goal; (b) planning autonomy, the autonomy to decide in what sequence different (sub-)tasks are approached and when this is done; and (c) decision autonomy, the general degree to which incumbents can make their own decisions at work." (Fisher et al. 2018, p. 232). Additionally, social support in the form of social interaction with other individuals to discuss work-related problems and challenges is needed in a workplace that supports learning (Fisher et al. 2018). Finally, it is also acknowledged that professional learning is a reciprocal process that combines the affordances of a workplace — such as resources, materials, and people - with the individual's ability and motivation to engage with what is afforded (e.g., Billett 2015; Littlejohn et al. 2016). Thus, how workers coordinate their professional development depends on both the sociocultural conditions of the workplace and on the workers' motivation, beliefs, ideals, interests, goals, competencies, work history, and personality (Eteläpelto 2017; Goller and Harteis 2017).

\section{Digitalization of Work}

Regarding digitalization, scholars have found that digitalization alters work in several ways and thus presents new opportunities and challenges regarding professional development and learning. Digitalization is a broad concept, which encompasses "the growing use of information and communication technologies (ICT) in every area of life" (Vuori, Helander, and Okkonen 2018, p. 1) while also referring to "the ways that digital media structure, shape, and influence the contemporary world" (Brennen and Kreiss 2014, para. 18). In contrast to digitization, which can be defined as "the material process of converting individual analogue streams of information into digital bits" (Brennen and Kreiss 2014, para. 5), digitalization or digital transformation refers to more fundamental changes in social life and changes in its structure due to digital technologies.

In this article, digitalization is approached especially from the perspective of how it may change work and learning in the future. There are several analyses of how digitalization, and especially automation, alters job skill demands and the labor market (e.g., Autor et al. 2003; Balsmeier and Woerter 2019; Frey and Osborne 2013; Muro et al. 2017). Digitalization is associated with increased employment of especially high-skilled labor (e.g., Balsmeier and Woerter 2019; Frey and Osborne 2013). It has been suggested that jobs involving routine work tasks and a lower level of complexity are more likely to be automated than non-routine tasks requiring highly cognitive skills (Autor et al. 2003; Frey and Osborne 2013). Recent large-scale analysis (Chui, Manyika, and Miremadi 2015 ) indicated that $45 \%$ of work tasks could be automated using current automation technologies, and 58\% in the near future. Frey and Osborne (2013, Frey et al. 2016) state that even high salary jobs (e.g., administrative managers and airplane pilots) are not safe from automation. Adoption of new digital tools can increase job demands, as digitalization requires the workers to add new tasks to their old jobs, which changes their job 
descriptions and competence requirements (Fisher et al. 2018). The change in the competencies required might result in concerns regarding worker's employability, especially for employees who are not experienced or confident with using new digital technologies (O'Driscoll et al. 2010; Rintala and Suolanen 2005).

Additionally, digitalization may result in a higher perception of job control by providing more freedom regarding the organization of work and in the assistance of more menial tasks (Fisher et al. 2018). It has been stated in several studies that as the accessing, sharing, gathering and analyzing of information becomes easier, employees will have new ways to collaborate with each other and access a broader range of work tasks, and have increased flexibility and freedom regarding where and when the work is done (e.g., Day et al. 2010; Dimicco et al. 2008; Fisher et al. 2018; O’Driscoll et al. 2010). However, the increased access to information may also lead to information overload, i.e., "a feeling of being overwhelmed by the quantity of incoming information and the need to respond to it" (O'Driscoll et al. 2010, p. 275). Consequently, asynchronous communication and the increased accessibility and availability have been found to facilitate the spillover of work to leisure time (Bordi et al. 2018). For instance, previous research has found that employees clear and check their email in the evenings and weekends in order to manage their work-related communication load and their overall workload (Barley et al. 2011; Bordi et al. 2018). Furthermore, the employees may feel strong pressure to be available and react immediately through digital communication devices in order to manage their work (Bordi et al. 2018). Thus, this increased access to information and striving for efficiency is closely related to work intensification, which occurs if employees feel the pressure to complete more tasks within a working day (Kubicek et al. 2014). According to Kubicek et al. (2014) work intensification is characterized by increased demands regarding 1) work pace and multitasking, 2) independent work planning and decision making, 3) independent career management and planning, 4) knowledge and learning, and 5) skills. Thus, the freedom to plan the work and workday autonomously according to individual preferences also increases the job requirements and requires the workers to take responsibility for their time and task management (Fisher et al. 2018).

Scholars have also found that new ICTs open new channels for finding and exchanging information, increased flexibility and control over workers' learning experiences, and a space for building social capital (e.g., Brookshire, Lybarger, and Keane 2011; Dimicco et al. 2008; Gerard 2012; Gruzd and Goertzen 2013; Vuori et al. 2018). For instance, social and mobile technologies can help workers to identify experts, solve problems, generate ideas and to share knowledge (DiMicco et al. 2009; Ellison et al. 2015; Turban et al. 2011), which will help employees who work remotely at different locations and at different times (Bordi et al. 2018; Day et al. 2010). Past research has indicated that users of social technologies in workplaces value especially the interactivity, peer support, and instant feedback offered by said technologies (Leino, TanhuaPiiroinen, and Sommers-Piiroinen 2012). However, despite its potential, automation has replaced human work at a slower pace than expected (Autor 2015). The main factors behind this are firstly related to social acceptance (to provide purposeful and meaningful life for the members of society; Nussbaum 2011), secondly to technological "bottlenecks" (social perception incl. Skills related to empathy, caring and negotiation; Deming 2015), and finally, to creativity (fine arts and originality; Frey and Osborne 2013). 


\section{Methods}

\section{Participants}

The data were collected from 81 Finnish government workers by using the method of empathy-based stories (MEBS) (Wallin, Koro-Ljungberg, and Eskola 2018) during spring 2017. The participants worked in various positions that ranged from secretaries and assistants to managers. The most common positions were "executives" and "managers" followed by "specialists" and "inspectors". Based on participants' selfreports, 9 (11.1\%) worked in administrative tasks, 30 (37.0\%) were experts, 17 (21.0\%) were senior experts, and $22(27.2 \%)$ were in manager positions. Three participants (3.7\%) did not report their work title. The participants ranged between 28 and 67 years of age $(M=50.1 ; S D=9.483)$, and $65 \%$ of the participants were born in the 1950 s and 1960s. The participants consisted of 48 women (59.3\%), 32 men (39.5\%) and one blank answer $(1.2 \%)$ in relation to the participant's gender. The request to take part in the research was distributed by email to all participants taking part in a national conference for government workers. In addition, the researchers contacted directly randomly selected government organizations.

Finnish government workers were chosen as the participants in this study because they represent an employee group which is currently working in an environment of continuous digital change and it has also been estimated that digitalization highly influences administrative work (Frey and Osborne 2013). The participants were also chosen because they belong to the category of "information-age knowledge workers," as they typically work in complex environments and are associated with qualities such as creativity, innovation, problem-solving, learning, ethics, and morale (Eskola 2018). Internationally, the trend of modernizing the public sector by using ICTs is referred to as electronic government or e-government, "a term that blurs the borders between public administration, new technology and changing administrative methods" (Nygren 2012, p. 616; see also Bekkers and Homberg 2007; Yildiz 2007). Furthermore, Finland was considered as a suitable country of choice for our study, as it is among the more advanced digital economies in the European Union. According to the Digital Economy and Society Index (DESI 2018), it is considered as one of the European Union leading countries in digitalization, especially in digital skills and public services. Additionally, digitalization in Finland is a prevalent theme in the program of the current government, and the Finnish State Treasury has been tasked with assisting in making government services more client-oriented and digital (State Treasury 2016).

\section{Method}

MEBS is a qualitative method of data collection through which participants write short imaginary texts based on an introductory script (i.e., frame story) designed by the researcher. With MEBS, there are at least two versions of a frame story, and these versions differ in respect to one aspect. This variation enables the researcher to study how the stories change when one element is varied. The varied element and format of the frame stories are derived from and are dependent on the research question(s), and there is usually a division between positive and negative elements, such as success and failure regarding a phenomenon. However, it is also possible to construct the variation 
around other elements (e.g., gender, time frame). Typically, frame stories describe an event or situation, and participants are instructed to continue the story or explain what has happened before the described situation (Wallin et al. 2018). In this research, our interest was to explore how digitalization might support or hinder professional development in the future. Thus, we used two frame stories (i.e., a positive frame story and a negative frame story) in which we asked participants to describe why digitalization had either supported or hindered the professional development of an imaginary person named Charlie:

- Positive frame story:

Imagine that the year is 2025. Charlie is thinking about his/her career and notices that digitalization has supported his/her professional development. Imagine yourself in his/her situation and describe why s/he believes that digitalization has had a positive effect on his/her professional development.

- Negative frame story:

Imagine that the year is 2025. Charlie is thinking about his/her career and notices that digitalization has hindered his/her professional development. Imagine yourself in his/her situation and describe why s/he believes that digitalization has had a negative effect on his/her professional development.

The two frame stories were first tested in a pilot study of ten individuals who provided hand-written responses to version A (positive) or B (negative) of the frame story during a face-to-face situation at their workplace. An analysis of the pilot study showed that all the stories were written according to the assignment, were appropriate, and answered the research questions. Thus, the pilot data were included in the final data set. After the pilot phase, data collection was carried out in one organization face-to-face (18 participants) and through an e-form that was distributed to Finnish government workers via email (53 participants). The participants could write their stories according to version $\mathrm{A}$, version $\mathrm{B}$, or both, and they were also asked to report their year of birth, gender, and work position. During the data collection (both face-to-face and electronic), the participants had an unlimited amount of time to write their stories, and they also had the option to continue writing later if needed. The final data used in this study ( 81 participants) consists of 28 participants who wrote their stories in a face-to-face situation and 53 participants who submitted their stories through e-forms. Overall, the 101 stories used in this study were collected either face-to-face or electronically through an e-form from 81 voluntary participants who were working in government organizations in Finland.

MEBS produces textual data that are suitable for examining participants' perceptions regarding a specific phenomenon. In comparison to interviews or other narrative methods, MEBS does not focus on researching personal experiences or life histories and thus, the stories portray plausible and potential connections and insights which might be based on the participants' own experiences, but they may also be the result of their imagination (Wallin et al. 2018). Hence, MEBS was well-suited for our purposes because we were interested in applying a future-orientation to explore the participants' underlying assumptions, expectations, and perceptions regarding digitalization and professional development. Additionally, as MEBS aims to spark the participants' imagination, MEBS data provide the researcher with an opportunity to determine 
Table 1 Positive $(n=68)$ and negative $(n=33)$ frame stories by gender, age and work role

\begin{tabular}{llr}
\hline & Frame story & Negative \\
\cline { 2 - 3 } Participants & Positive & $N(\%)$ \\
\hline Gender $(N=80)^{1}$ & $N(\%)$ & $17(25.0)$ \\
Female $(n=48)$ & & $15(32.9)$ \\
Male $(n=32)$ & $41(75.0)$ & \\
Age $(N=78)^{2}$ & $26(67.2)$ & $3(17.9)$ \\
$28-39$ years $(n=14)$ & & $8(40.1)$ \\
$40-49$ years $(n=15)$ & $12(82.2)$ & $15(31.9)$ \\
$50-59$ years $(n=33)$ & $11(59.4)$ & $6(22.0)$ \\
$60-67$ years $(n=16)$ & $27(68.2)$ & $3(33.3)$ \\
Work role $(N=78)^{2}$ & $15(78.2)$ & $12(26.7)$ \\
Administrative personnel $(n=9)$ & & $7(26.5)$ \\
Expert $(n=30)$ & $6(66.7)$ & $10(31.9)$ \\
Senior expert $(n=17)$ & $26(73.3)$ & \\
Manager $(n=22)$ & $15(73.5)$ & $18(68.1)$ \\
\hline
\end{tabular}

${ }^{1}$ One missing value

2 Three missing values

new perspectives, verbalize tacit knowledge and amass unexpected viewpoints that might have been lost with other methods (Wallin et al. 2018). MEBS also made it possible for us to collect qualitative data from a wider sample than with interviews because empathy-based stories can be written anytime and anywhere, and the stories can be written in a relatively short time.

\section{Data Analysis}

The participants $(N=81)$ wrote 101 stories in total (20 participants chose to answer both frame stories). These stories ranged from a few sentences to essays consisting of up to 870 words, with a total word count of 15,393 words. The data comprised $68(67.3 \%)$ positive stories and $33(32.7 \%)$ negative stories. Most of the participants $(n=48,59.3 \%)$ wrote a positive story, $13(16.0 \%)$ wrote a negative story, and $20(24.7 \%)$ wrote both stories. Table 1 shows how positive and negative stories were distributed by participants' age, gender and work title. Participants' titles were categorized into four work roles: Administrative personnel (e.g., "Secretary", “Translator”), Experts (e.g., "Customs Inspector", “Application Specialist"), Senior experts (e.g., "Leading District Attorney", "Chief Medical Officer") and Managers (e.g., "Head of Unit", "Development Director"). The statistical relationship between the nature of stories (positive, negative, both positive and negative) and background variables (gender, age, work title) was investigated with Bayesian nominal indicator classification modeling (Myllymäki, Silander, Tirri, and Uronen 2002). Analysis based on machine learning approach showed that government workers' age, gender or work title did not predict their preferences of writing positive, negative or both types of stories related to professional development and digitalization. 
The transcribed stories were analyzed inductively using qualitative thematic analysis in order to identify common themes. NVivo software (version 11) was used to isolate, sort, and code text segments and identify emerging themes within the participants' stories. First, the stories were read several times to obtain an overall sense of the data, with attention paid to how the participants described the ways digitalization might support or hinder Charlie's professional development. Second, text segments comprising one or more sentences were coded into sub-themes according to the research questions and versions of the frame story. Hence, during this first phase of analysis, the positive and negative stories were analyzed separately. In the second phase, we compared the sub-themes, and as a result, three interrelated themes (work tasks, work practices and knowledge development and management) were formed from the similarities and differences in these themes. Finally, in order to synthesize the data and illustrate the findings, we constructed two typical scenarios (positive and negative) by selecting data extracts, which describes the themes formed earlier. Thus, the content of the scenarios is derived from several stories (the researchers added or deleted a few words to improve readability) and the formation of the scenarios was guided by Polkinghorne's (1995) description of narrative analysis.

\section{Results}

In the frame stories, we asked the participants to imagine why digitalization had either supported or hindered the professional development of Charlie in the future. In both the positive and negative stories, the participants connected digitalization with similar changes in their working lives, yet the stories differed regarding how Charlie responded to these changes and how the changes affected workplace learning potential as a result. In other words, in most stories, the participants described similar changes as both hindering and supporting professional development. In this section, we first introduce two scenarios, one positive and one negative, which summarize the findings presented in detail thereafter. We used data extracts to illustrate the findings, and in order to identify the story extracts, the stories were numbered and named according to the frame story version (for example P1 stands for the first positive story).

Positive Scenario How might digitalization support professional development in the future?

Charlie's work tasks have become more versatile and Charlie has been able to develop a great deal of her/his professional skills. The advancement of digitalization has created both new opportunities for professional development and more demanding tasks that motivate Charlie to move forward. Charlie feels that as simpler tasks have shifted to robots, $\mathrm{s} /$ he has more time to focus on the development of her/his core competencies. Administrative applications also interact with each other automatically, eliminating the need for spending time on reporting working hours. With fewer pending routines, Charlie has more time to focus on planning and analysis. 
Applications and systems also allow Charlie to work anywhere and anytime. Attending a meeting is possible even if you are on a bike, which frees up time for professional development. Work in most cases is now done in interactive electronic workspaces that have been developed to serve work processes. Increased interactivity has fostered the exchange of ideas between workers. At the same time, quite unnoticed, networks have become to exist everywhere. Charlie has also been involved in digitalization projects and professional development through this work. Developing one's skills and learning new things has become easier with the advent of e-learning and access to information, as well as management. Learning new things and studying is no longer dependent on time and place. The amount of study material is much more extensive and easier to find online in electronic format. In addition, networking and interaction with other learners is easier and promotes learning in a whole new way.

Negative Scenario How might digitalization hinder professional development in the future?

Digitalization has made even simpler tasks more complicated and time-consuming. Much of Charlie's previous work has been automated, and her/his own job is not well controlled when it comes to doing things differently from before. In addition, in order to complete core work tasks, there is a constant pressure to adopt to new information systems and participate in their development and testing. A huge amount of working time is allocated to tasks other than those that are related to Charlie's areas of expertise. Charlie wonders why s/he feels that s/he is a member of the IT department, although her/ his own areas of expertise are somewhere else. Digitalization has also made the work more hectic; everything should be ready right away and there will never be enough time to concentrate and reflect on long-term high-quality work processes. Charlie receives a constant flow of email, instant messaging (Lync), and phone queries on trivial topics. In addition, technology is not up to the task: the picture disappears and, in a moment, the sound also disappears. Systems are also changing all the time and knowledge databases are so vast that it is difficult to find relevant information at any given time. Face-to-face contact with clients, co-workers and colleagues is rare and no one is physically present in the workplace - everyone is doing distance work, or they are out in the field. The work is lonely and virtual, and Charlie misses person-to-person contact to deepen different aspects of the work. In the past, Charlie's co-workers were right next door and s/he felt somehow more important as he/she was able to share knowledge with others. The training provided by the employer mainly focuses on new electronic systems and their introduction. Instead, the content of the work that Charlie would like to develop has been pushed back as a side issue.

\section{Changes in Work Tasks}

Both in the positive and negative stories, the participants connected digitalization with changes in Charlie's work tasks and routines. As robots and automation became more 
common, Charlie's old work tasks, which were often mechanical, manual, and routinized, were replaced with more challenging work tasks that required more thinking and expertise. In the positive stories, digitalization was described as being desirable, as the automation of routine work tasks allowed Charlie to deepen his/her core competencies and freed time for developmental activities as well as more interesting, versatile, and challenging tasks. The change in work routine was described as highly motivating and empowering, and it was connected to efficiency, new competencies, and a more pleasant work role:

My work tasks have changed, so I only focus on genuinely challenging jobs that require human reflection. [...] 90\% of my administrative decisions and solutions are made automatically using artificial intelligence, robotics, and solution databases. For me, it means that I only do interesting jobs. Routine jobs have been left to the machines. The change has also made it possible for me to develop professionally, unlike in the past, since nowadays, I have time to study and develop myself (P48).

Similarly, in the negative stories, the participants connected digitalization with automation and efficiency, but in contrast to the positive stories, the negative stories described the changes as undesirable and resulting in an increased workload and time management problems. In the negative stories, digitalization was viewed as contributing to a hectic pace of work, multitasking, and interruptions. These elements presented challenges to the daily execution of work tasks and reduced available time for the work that required deeper focus and more long-term commitment. In addition, technological shortcomings, such as poor usability of software, inadequate information systems, and malfunctioning network connections, were frequently described as hindering and slowing down the execution of work tasks, thus leading to anxiety and inefficiency.

Consequently, in these stories, the changing work tasks and adoption of new digital tools were considered burdens that hindered Charlie's professional development. Charlie felt like s/he was spending more time working on the adoption, development, and testing of new information systems and software than on "actual" work, which s/he felt competent in and had been educated for. Furthermore, in some negative stories, digitalization was also connected with unemployment, as the original work tasks were performed by robots, and replacement work tasks were either not offered to Charlie, or Charlie was not able or willing to adapt to the new work role. Thus, in the negative stories, the changing work tasks led to feelings of incompetence and redundancy. The stories described how especially administrative workers were laid off, and their work tasks, such as billing for travel costs, were allocated to the remaining personnel. The new work did not match Charlie's current competencies or professional identity, and s/ he felt that his/her opportunities for development were restricted by the employer, or s/ he was not motivated to develop his/her competencies to meet new demands:

Charlie has never been very interested in technology or ICT skills. Learning new tools and systems has always been a must for him/her. Employers have also noticed this. Charlie would like to do his/her "basic job" well, but it hasn't been 
possible for a long time without first having to learn all the nerdy stuff. The work has become burdensome and repulsive (N8).

\section{Changes in Work Practices}

In addition to changing work tasks, digitalization was also connected to changes in work practices in both the positive and negative stories. The stories described an increase in remote, virtual and global work and the utilization of new kinds of workspaces. When changing work practices were described as supporting professional development, the participants emphasized how the online communication channels supported interaction and networking:

Online discussions with colleagues around the world are particularly rewarding. Occasionally, even several times a week, we discuss work-related topics with a group of people and share tips on how to work in different situations. [...] Digitalization has, in a way, expanded collegial cooperation and the learning network beyond its own organization and made it a global community (P80).

According to the participants' views, ICT may facilitate social networking and communication across physical distances, thereby enabling increased interaction and communication within Charlie's organization and in other professional networks. According to the participants, this increased interaction can result in fruitful and productive discussions with coworkers all over the world, thus helping to build a virtual and global learning network that is not limited to organizational boundaries. In the positive stories, remote work was also considered to be a positive aspect in terms of the flexibility and independence it offers, as it makes working possible, anytime and anywhere. This flexibility supported Charlie's management of his/her work-life balance and enabled more free time for developmental activities.

On the other hand, the new work practices, especially remote work, were also connected with a loss of communality and feelings of loneliness. In contrast to the positive stories, in the negative stories, online communication and remote work decreased interaction in the work community and hindered the sharing and transfer of knowledge as a result. In these stories, online interaction was connected with superficiality, and Charlie expressed a need to have discussions with other experts and colleagues in a face-to-face manner in order to deliberate on work issues:

According to Charlie, it would be important to get face-to-face with other experts in the same field, because only then can you really deepen your thoughts and exchange ideas. In Charlie's opinion, s/he is often left alone with the computer, and the employer also requires the work to be done in an open-plan office and, when necessary, with headphones and remotely. The work is lonely and virtual, and Charlie longs for human contact through which s/he could deepen different aspects of the work (N45). 


\section{Changes in Knowledge Development and Management}

Knowledge development and management were frequently connected to professional development, especially in the positive stories. In these stories, the participants perceived that digitalization might improve the availability and management of workrelated information and knowledge by providing efficient access to different repositories. Intranets, social media, and the Internet were described as important resources for finding and locating work-related information in a fast, easy, and independent manner:

Digitalization has made it possible to update professional knowledge proficiently: Both scientific knowledge and publications as well as more experiential blog and picture stories can be found on the web. Also, different online courses, streams, etc. help, in that you do not always have to be present at a particular time-you can develop and update your skills whenever it suits you (P80).

The participants also emphasized e-learning and online courses as important resources for professional development and learning. Online courses and lectures provided Charlie with a flexible and self-directed way of updating his/her knowledge and competencies, regardless of time and place. The participants also emphasized how the opportunity to engage in online courses expanded learning options, and how up-todate course materials supported learning. In addition to formal online courses, the participants also acknowledged the importance of using other online sources, such as videos and podcasts, for knowledge development.

In addition to the independent and self-directed ways of knowledge development described above, some stories also described how participating in different digital projects and workshops supported Charlie's professional development and learning. According to the stories, being part of developmental processes and solving problems with other workers might inspire and encourage workers to learn and feel useful in terms of their contribution to the organization and other workers.

The negative stories also described the increased use of alternative sources of digital knowledge, although to a lesser extent than in the positive stories. In these stories, the participants emphasized how the digitization of information might lead to decreased trustworthiness in terms of information, and information management was considered a challenging task because of the constant information overload and change.

\section{Discussion}

In this article, we explored Finnish government workers' stories about how digitalization could influence work and support or hinder professional development in the future. According to the findings, both the supporting and hindering factors stem from similar and interrelated changes in the work - namely, changes in work tasks, work practices, and knowledge development and management. The stories illustrated how digitalization may affect the learning potential of a workplace (e.g., Ellstrom 2011; Eraut 2007) in various ways, and thus create different affordances and constraints for professional development. For instance, in line with previous analyses regarding the future of 
digitalization and work (Autor et al. 2003; Balsmeier and Woerter 2019; Frey and Osborne 2013; Muro et al. 2017), the findings showed how digitalization might in the future change the task characteristics and competence requirements of work by replacing routine work tasks with more challenging work tasks. In the positive stories, changes in work tasks enabled Charlie to develop his/her competences and skills as it resulted in a decrease of workload and more time for interesting work tasks. This finding supports earlier research, where digitalization and automation of meanial activities has also been associated with a reduced workload and more interesting work tasks (Fisher et al. 2018).

However, the negative stories framed a different picture, as in these stories changes in work tasks restricted professional development by leading to an increase of workload and feelings of incompetence and redundancy. Thus, the findings indicate that digitalization may also lead to work intensification (Kubicek et al. 2014), i.e., multitasking and increased demands related to for example knowledge, skills and career development. For instance, in the negative stories Charlie felt like the new work tasks did not match with his/her competencies and he/she was unwilling or unable to meet the new demands because of lack of confidence, time or professional training and support. In some negative stories, digitalization led also to the disappearance of old work tasks, while at the same time, new work tasks were not offered, or professional training regarding new work tasks was insufficient. Over time, this led to marginalization and unemployment. These findings indicate that digitalization may potentially offer workers with challenges and demanding work activities by affecting task variety and complexity (see, e.g., Ellstrom 2011; Eraut 2007; Fisher et al. 2018), but how this impact professional development remains ambivalent due to various inidividual and contextual factors.

Additionally, the stories illustrated how changes in work practices, and in particular the increase in distant work and digital communication may act as a "double-edged sword" in regard of professional development. For instance, the positive stories described how digitalization might result in increased opportunities for networking and participation in developmental activities, whereas in the negative stories distant work and the increase of online communication were considered to decrease interaction and communality, and thus hinder knowledge sharing and social support. Hence, these findings highlight the role of social support and relationships in professional development and learning (e.g., Ellstrom 2011; Eraut 2007), but also addresses that the role of digitalization in supporting interactivity is perceived as twofold.

In line with previous studies (e.g., Fisher et al. 2018), digitalization was also connected to a higher degree of job control by providing flexibility in terms of, for example, when and where to work. Hence, although distant work was considered to decrease interaction and communication in the negative stories, it was also valued because of its potential to provide opportunities for job control. Previous studies have found that the asynchrony and increased flexibility offered by digitalization blurs the boundary between work and leisure time and causes difficulties to disconnect from work (e.g., Bordi et al. 2018; Vuori et al. 2018). Interestingly, participants of our study viewed the opportunity to flexibly combine work and non-work domains as mostly something positive and supporting professional development (e.g., participation in professional online networks and courses regardless of time and place). Only one negative story described how the increased accessibility and availability caused by 
digitalization might result in a negative spillover of work to leisure time. Yet, this positive overall tone may be partly affected by Finnish high level of digitalization (DESI 2018) and legislative promotion of flexible work (Finnish Ministry of Employment and the Economy 2011). Furthermore, the disparity between the negative and positive stories, as well as the earlier research, may also be due to the fact that in the frame stories the participants were instructed to describe how digitalization has influenced Charlies' professional development. Consequently, negative effects may have been left out from the stories because the participants' do not necessarily connect them with Charlies' professional development but rather to issues related to for example his/ her wellbeing.

In addition to changes in work tasks and practices, the stories described how digitalization brings new ways to knowledge development and management. The stories mentioned e-learning, online courses, and videos as important resources for professional development and learning. The participants' valued especially diverse forms of up-to-date learning materials and the opportunity for information acquisition and sharing in a networked environment, but also expressed a fear that the diversity of information and constant change might lead to information overload. However, these negative aspects stood out to a much lesser extent than the positive. Thus, these results indicate that the participants consider digitalization as mostly supporting knowledge development and management in the future, but at the same time acknowledges the need for new knowledge management skills in order to avoid the negative consequences of digitalization, such as information overload.

\section{Limitations and Recommendations}

A number of potential limitations need to be considered when interpreting the findings. First, although the study was based on a multi-organizational sample, all the participants worked for the Finnish government, and the sample size was relatively small. Thus, the findings might not be transferable to broader contexts (e.g., other professional fields or government workers in other countries). Thus, further research should be conducted in different work contexts in order to verify and extend the findings. Second, the participants represented different generations and thus, their different histories of technological use and different career stages need to be taken into account when interpreting the findings. Third, an interesting finding in this study was that most participants chose to write in response to the positive version of the frame story. This may be reflective of the fact that government workers possess in general more positive than negative perceptions of the future (see also Fisher et al. 2018), but one could also speculate that this may reflect a self-selection bias (i.e., the participants who possessed a positive stance were more willing to take part in the study than those with a negative stance). However, these limitations do not limit the value of this study, as the aim was not to generate generalizable findings, but to develop insights into the topic. Hence, in the future both qualitative studies and quantitative studies are needed to complement and validate these findings. A particularly interesting aspect would be to analyze what kind of agentic actions or strategies workers adopt when engaging with digitalization at work.

MEBS was used in this study to examine the participants' perceptions of the future. Hence, it is important to note that empathy-based stories are plausible imaginary stories 
that portray possible and potential connections and insights rather than focusing on presenting personal lived experiences. Yet, in MEBS "the ability of the stories to reflect and express personal meaning is considered more relevant than the factual occurrence of the events described in the stories" (Wallin et al. 2018, p. 7). For the purposes of this study, several reasons justify the choice of the method. Firstly, MEBS offered the participants an opportunity to use their imagination and to freely choose what to include in their stories. Thus, the study adds knowledge about the expectations, hopes and fears government workers associate with digitalization and professional development. Secondly, the fact that the stories are not necessarily fictional, and that in this study many participants chose to write their stories in the first-person and not as Charlie, as well as the similarity of the stories, support the notion that the stories illustrate shared sociocultural beliefs. Thirdly, in contrary to earlier studies exploring the lived experiences of the participants with for example interviews (e.g., Fisher et al. 2018) that often concentrate on retrospective experiences, MEBS provided the researchers a useful tool for exploring the participants' perceptions of the future.

\section{Conclusions}

This research has illustrated government workers' perceptions regarding digitalization of work and professional development. In common with the positive and negative stories is that they both describe how professional learning and development happens in everyday (work) activities, includes both formal and informal ways of learning, and requires proactivity and self-directedness. This finding is in line with the current view that the professional development of workers' is not only the responsibility of the training department but workers' must manage their own professional development and learning in order to stay effective in the working force (e.g., Billett 2015; Billett and Noble 2017; Littlejohn et al. 2016; Poell et al. 2018). However, the findings also reflected different understandings of what is seen as professional development. In the positive stories the adoption of different digital tools and attaining for example digital workshops were described as a part of Charlies' professional development, whereas in the negative stories learning new digital ways of working was considered as a burden and not as a part of his/her professional development. As such, these diverse understandings not only reflected different conceptualizations of professional development, but they also reflected how individuals may position themselves differently regarding digitalization. Narrative inquiry and textual decisions communicate authorial understandings of participants, their subjectivities, and their experiences, but also a writer's understandings of power and position (Holley and Colyar 2009). For instance, in a recent interview study, administrative workers possessed rather optimistic views of the effects of digitalization on workplace learning and associated it generally with something positive (Fisher et al. 2018). This study complements these findings by illustrating also the negative views workers possess regarding digitalization and professional development. The recognition of technology-related demands and the resources needed to buffer these demands is important in order to manage and avoid the negative consequences of digitalization.

This article provides scholars and practitioners of human resources with insights as to how digitalization might support or hinder worker's professional development in the 
future. In sum, the findings illustrate the double-edged nature of digitalization, as it may both support and hinder professional development and learning by changing work tasks, work practices and knowledge development and management. The stories revealed that digitalization may support professional development especially by providing opportunities for job control in terms of flexibility, and new ways for knowledge development and management. Additionally, in order to support professional development and learning in the work force of the future, the findings illustrated the importance of 1) tailoring the changing work tasks and activities in ways that support worker's experience of competence, 2) providing functioning software and systems, 3 ) providing individually targeted training, guidance and social support when implementing new technologies, and 4) involving workers in the design and development of digital changes. Overall, when digitalizing work, organizations need to be aware of differences in professionals' subjectivities (i.e., valuations, beliefs, and expectations) in order to efficiently support professional development. The findings highlight the need for trainers and managers to invest in the enhancement of overall technological selfefficacy and ways to cope individually with the range of demands related to digitalization, such as interruptions, information overload and work intensification.

\section{Compliance with Ethical Standards}

Conflict of Interest The authors declare that they have no conflict of interest.

Open Access This article is licensed under a Creative Commons Attribution 4.0 International License, which permits use, sharing, adaptation, distribution and reproduction in any medium or format, as long as you give appropriate credit to the original author(s) and the source, provide a link to the Creative Commons licence, and indicate if changes were made. The images or other third party material in this article are included in the article's Creative Commons licence, unless indicated otherwise in a credit line to the material. If material is not included in the article's Creative Commons licence and your intended use is not permitted by statutory regulation or exceeds the permitted use, you will need to obtain permission directly from the copyright holder. To view a copy of this licence, visit http://creativecommons.org/licenses/by/4.0/.

\section{References}

Autor, D. H. (2015). Why are there still so many jobs? The history and future of workplace automation. The Journal of Economic Perspectives, 29(3), 3-30.

Autor, D. H., Levy, F., \& Murnane, R. J. (2003). The skill content of recent technological change: An empirical exploration. The Quarterly Journal of Economics, 118(4), 1279-1333.

Balsmeier, B., \& Woerter, M. (2019). Is this time different? How digitalization influences job creation and destruction. Research Policy, 48, 1-10.

Barley, S. R., Meyerson, D. E., \& Grodal, S. (2011). Email as a source and symbol of stress. Organization Science, 22(4), 887-906.

Bekkers, V., \& Homberg, V. (2007). The myths of e-government: looking beyond the assumptions of a new and better government. The Information Society, 23(5), 373-382.

Billett, S. (2001). Learning through work: workplace affordances and individual engagement. Journal of Workplace Learning, 13(5), 209-214.

Billett, S. (2015). Work, discretion and learning: processes of life learning and development at work. International Journal of Training Research, 13(3), 214-230.

Billett, S., \& Noble, C. (2017). Individuals' mediation of learning professional practice: Co-working and learning to prescribe. In M. Goller \& S. Paloniemi (Eds.), Agency at work: An agentic perspective on professional learning and development (pp. 205-227). Cham: Springer. 
Bordi, L., Okkonen, J., Mäkiniemi, J.-P., \& Heikkilä-Tammi, K. (2018). Communication in the digital work environment: implications for wellbeing at work. Nordic Journal of Working Life Studies, 8(S3), 29-48.

Brennen, S., \& Kreiss, D. (2014). Digitalization and Digitization. Retrieved from: http://culturedigitally. org/2014/09/digitalization-and-digitization/.

Brookshire, R. G., Lybarger, K. M., \& Keane, L. B. (2011). Virtual workplace learning: Promises met. In M. Malloch, L. Cairns, K. Evans, \& B. N. O’Connor (Eds.), The SAGE handbook of workplace learning (pp. 331-340). Thousand Oaks: SAGE.

Cheetham, G., \& Chivers, G. (2001). How professionals learn in practice: An investigation of informal learning amongst people working in professions. Journal of European Industrial Training, 25(5), 247-292.

Chui, M., Manyika, J., \& Miremadi, M. (2015). Four fundamentals of workplace automation. McKinsey.

Collin, K., Van der Heijden, B., \& Lewis, P. (2012). Continuing professional development. International Journal of Training and Development, 16(3), 155-163.

Day, A., Scott, N., \& Kelloway, E. K. (2010). Information and communication technology: Implications for job stress and employee wellbeing. In P. L. Perrewé \& D. C. Ganster (Eds.), New Developments in Theoretical and Conceptual Approaches to Job Stress (pp. 317-350). Emerald.

Deming, D. J. (2015). The Growing Importance of Social Skills in the Labor Market. The National Bureau of economic research working paper no. 21473. Cambridge, MA: NBER.

Digital Economy and Society Index. (2018). Retrieved from: https://ec.europa.eu/digital-singlemarket/en/scoreboard/finland.

DiMicco, J., Millen, D.R., Geyer, W., Dugan, C., Brownholtz, B, \& Muller, M. (2008). Motivations for social networking at work. Proc. CSCW 2008. ACM, 711-720.

DiMicco, J., Geyer, W., Millen, D. R., Dugan, C., \& Brownholtz, B. (2009). People sensemaking and relationship building on an enterprise social networking site. Proceedings of the 42nd Annual Hawaii International Conference on System Sciences. https://doi.org/10.1109/hicss.2009.343.

Ellison, N.B., Gibbs, J.L., \& Weber, M.S. (2015). The use of enterprise social network sites for knowledge sharing in distributed organizations: the role of organizational affordances. American Behavioral Scientist, 59, 103-123.

Ellstrom, P.-E. (2001). Integrating learning and work: Problems and prospects. Human Resource Development Quarterly, 12(4), 421-435.

Ellstrom, P.-E. (2011). Informal learning at work: Conditions, processes and logics. In M. Malloch, L. Cairns, K. Evans, \& B. N. O'Connor (Eds.), The SAGE handbook of workplace learning (pp. 105-119). London: SAGE.

Eraut, M. (2007). Learning from other people in the workplace. Oxford Review of Education, 33(4), 403-422.

Eskola, A. (2018). Knowledge work and new ways of working. In A. Eskola (Ed.), Navigating through changing times: Knowledge work in complex environments (pp. 3-18). New York: Routledge, Taylor \& Francis Group.

Eteläpelto, A. (2017). Emerging conceptualisations on professional agency and learning. In M. Goller \& S. Paloniemi (Eds.), Agency at work: An agentic perspective on professional learning and development (pp. 183-201). Cham: Springer.

Finnish Ministry of Employment and the Economy. (2011). Working Hours Act (605/1996). https://www. finlex.fi/en/laki/kaannokset/1996/en19960605_20100991.pdf.

Fisher, C., Goller, M., Brinkmann, L., \& Harteis, C. (2018). Digitalisation of work: Between affordances and constraints for learning at work. In D. Ifenthaler (Ed.), Digital workplace learning (pp. 227-248). Springer: Cham.

Frey, C. B., \& Osbourne, M. A. (2013). The future of employment: How susceptible are jobs to computerization? Oxford: University of Oxford.

Frey, C. B., Osborne, M. A., \& Holmes, G. (2016). Citi GPS: Global perspectives \& solutions. University of Oxford.

Fuller, A., \& Unwin, L. (2004). Expansive learning environments: Integrating organisational and personal development. In H. Rainbird, A. Fuller, \& A. Munroe (Eds.), Workplace learning in context (pp. 126144). London: Routledge.

Gerard, J. P. (2012). Linking in with LinkedIn®: three exercises that enhance professional social networking and career building. Journal of Management Education, 36(6), 866-897.

Goller, M., \& Harteis, C. (2017). Human agency at work: Towards a clarification and operationalisation of the concept. In M. Goller \& S. Paloniemi (Eds.), Agency at work: An agentic perspective on professional learning and development (pp. 85-104). Cham, Switzerland: Springer.

Gruzd, A., \& Goertzen, M. (2013). Wired academia: why social scholars are using social media. 46th Hawaii international conference on system sciences, 3332-3341. 
Harteis, C. (2018). Machines, change and work: An educational view on the digitalization of work. In C. Harteis (Ed.), The impact of digitalization in the workplace: An educational view (pp. 1-12). Cham, Switzerland: Springer.

Havnes, A., \& Smeby, J.-C. (2014). Professional development and the profession. In S. Billett, C. Harteis, \& H. Gruber (Eds.), International handbook of research in professional and practice-based learning (pp. 915-954). Dordrecht: Springer.

Holley, K. A., \& Colyar, J. (2009). Rethinking texts: narrative and the construction of qualitative research. Educational Researcher, 38(9), 680-686.

Janis, I. L. (1982). Groupthink (2nd ed.). Boston: Houghton Mifflin.

Johnson, J. V., \& Hall, E. M. (1988). Job strain, work place social support, and cardiovascular disease: a crosssectional study of a random sample of the Swedish working population. American Journal of Public Health, 78(10), 1336-1342.

Karasek, R. A. (1979). Job demands, job decision latitude, and mental strain: Implications for job redesign. Administrative Science Quarterly, 24(2), 285-308.

Krumpal, I. (2013). Determinants of social desirability bias in sensitive surveys: a literature review. Quality and Quantity, 47(4), 2025-2047.

Kubicek, B., Korunka, C., Paškvan, M., Prem, R., \& Gerdenitsch, C. (2014). Changing working conditions at the onset of the twenty-first century: Facts from international datasets. In C. Korunka \& P. Hoonakker (Eds.), The impact of ICT on quality of working life (pp. 25-41). Dordrecht, The Netherlands: Springer Science Business Media.

Leino, J., Tanhua-Piiroinen, E., \& Sommers- Piiroinen, J. (2012). Adding social media to e-learning in the workplace: instilling interactive learning culture. International Journal of Advanced Corporate Learning (iJAC), 5(3), 18-25.

Littlejohn, A., Milligan, C., \& Margaryan, A. (2012). Charting collective knowledge: supporting self-regulated learning in the workplace. Journal of Workplace Learning, 24(3), 226-238.

Littlejohn, A., Milligan, C., Fontana, R. P., \& Margaryan, A. (2016). Professional learning through everyday work: How finance professionals self-regulate their learning. Vocations and Learning, 9(2), 207-226.

Muro, M., Liu, S., Whiton, J., \& Kulkarni, S. (2017). Digitalization and the American workforce. Washington: Brookings Institution.

Myllymäki, P., Silander, T., Tirri, H., \& Uronen, P. (2002). B-course: A web-based tool for Bayesian and causal data analysis. International Journal on Artificial Intelligence Tools, 11(3), 369-387.

Nussbaum, M. C. (2011). Creating capabilities: The human development approach. Cambridge, MA: Belknap Press of Harvard University Press.

Nygren, K. G. (2012). Narratives of ICT and organizational change in public administration. Gender, Work and Organization, 19(6), 615-630.

O’Driscoll, M. P., Brough, P., Timms, C., \& Sawang, S. (2010). Engagement with information and communication technology and psychological well-being. In P. L. Perrewé \& D. C. Ganster (Eds.), New Developments in Theoretical and Conceptual Approaches to Job Stress (pp. 269-316). Emerald.

Poell, R. F. \& Lundgren, H., Bang, A., Justice, S.B., Marsick, V.J., Sung, S., \& Yorks, L. (2018). How do employees' individual learning paths differ across occupations? A review of 10 years of empirical research. Journal of Workplace Learning, 30(5), 315-334.

Polkinghorne, D. E. (1995). Narrative configuration in qualitative analysis. In J. A. Hatch \& R. Wisniewski (Eds.), Life history and narrative (pp. 5-23). London: Falmer Press.

Rintala, N., \& Suolanen, S. (2005). The implications of digitalization for job descriptions, competencies and the quality of working life. Nordicom Review, 26(2), 53-67.

Schuman, H., \& Presser, S. (1981). Questions and answers in attitude surveys: Experiments on question form, wording, and context. Orlando, FL: Academic Press.

State Treasury. (2016). State Treasury boosts digitalization in public administration. http://www.statetreasury. fi/en-US/Agencies_and_institutions/Digitalisation/State_Treasury_boosts_digitalisation_in_(57273).

Timperley, H. (2011). Realizing the power of professional learning. Maidenhead: Open University Press.

Turban, E., Bolloju, N., \& Liang, T-P. (2011). Enterprise social networking: opportunities, adoption, and risk mitigation. Journal of Organizational Computing and Electronic Commerce, 21(3), 202-220.

van der Heijden, P. G. M., van Gils, G., Bouts, J., \& Hox, J. J. (2000). A comparison of randomized response, computer-assisted self-interview, and face-to-face direct questioning: Eliciting sensitive information in the context of welfare and unemployment benefit. Sociologial Methods \& Research, 28, 505-537.

Vuori, V., Helander, N., \& Okkonen, J. (2018). Digitalization in knowledge work: The dream of enhanced performance. Technology \& Work: Cognition.

Wallin, A., Koro-Ljungberg, M., \& Eskola, J. (2018). The method of empathy-based stories. International Journal of Research and Method in Education. 
Webster-Wright, A. (2009). Reframing professional development through understanding authentic professional development. Review of Educational Research, 79(2), 702-739.

Yildiz, M. (2007). E-government research: Reviewing the literature, limitations and ways forward. Government Information Quarterly, 24(3), 646-665.

Publisher's Note Springer Nature remains neutral with regard to jurisdictional claims in published maps and institutional affiliations.

M.Ed. Anna Wallin is a doctoral student at Tampere University, Finland. Her primary research interests include issues related to workplace learning, professional development and developments of qualitative methods. In her doctoral study she explores workers' professional development and the digitalization of working life in various contexts.

Dr. Laura Pylväs is a postdoctoral researcher at the University of Helsinki, Finland. Her primary research interests are focused on vocational and professional expertise, workplace learning, and regulation of learning.

Dr. Petri Nokelainen is a full professor of Engineering Pedagogy at the Tampere University, Finland. His research interestes are related to regulation of learning, emotions and development of expertise in engineering higher education, vocational education and working life. 